\section{Intraocular pressure before and after visual field examination}

L Martin

\begin{abstract}
Purpose To evaluate the influence of visual field (VF) examinations using modern techniques with short examination times on the intraocular pressure (IOP). Methods Sixty-one consecutive patients, aged 28-90 years, 40 women and 21 men, were examined. Forty patients were treated for glaucoma and 21 were untreated patients with ocular hypertension or suspected glaucoma. Twenty-one subjects were examined using the Humphrey Field Analyzer, using SITA programs, and 40 with high-pass resolution perimetry (HRP). Goldmann applanation tonometry was performed immediately before and after the VF examinations. Results A difference in IOP of more than $2 \mathrm{~mm} \mathrm{Hg}$ before and after the VF examination was observed in 14 of the 61 patients $(23 \%)$. The maximum change in each direction was $4 \mathrm{~mm} \mathrm{Hg}$. The mean differences were not significant. All eight subjects with increasing IOP after VF examinations were examined using the HRP technique $(P=0.04)$.

Conclusion Modern VF techniques with short examination time do not seem to significantly influence IOP.

Eye (2007) 21, 1479-1481; doi:10.1038/sj.eye.6702552; published online 6 October 2006
\end{abstract}

Keywords: intraocular pressure; tonometry; visual field; perimetry

\section{Introduction}

Tonometry and visual field (VF) examinations are essential in glaucoma diagnosis and followup. ${ }^{1}$ The accuracy and intra- and inter-test variability of the most common used method, the Goldmann applanation tonometry, have been extensively investigated, ${ }^{2}$ and are currently discussed in relation to corneal thickness. ${ }^{3-5}$ Tonometry results are influenced by many other factors, for example, time of the day for the measurement, ${ }^{6}$ the calibration of the equipment, the amount of fluid intake immediately before the intraocular pressure (IOP) measurement, ${ }^{7}$ pressure against the lids, ${ }^{8}$ tight collars, ${ }^{9}$ accommodation, ${ }^{10}$ and also the examiner. ${ }^{11}$ The normal variability between observers is reported to be $2-3 \mathrm{~mm} \mathrm{Hg}{ }^{11}$

Recently, Recupero et $a l^{12}$ published a study showing difference in IOP readings before and immediately after VF examinations using the Humphrey Visual Field Analyzer (HFA) in glaucoma patients. The effect was most marked in elderly patients. ${ }^{12}$ The maximum increase in IOP was $11 \mathrm{~mm} \mathrm{Hg}$. Lack of accommodation was proposed as one of many possible reasons for IOP increase after VF examinations. ${ }^{12}$

During the past decades, new examination algorithms and new perimetric techniques have been developed, with the specific aim to decrease examination time in order to increase quality and accuracy of the examination. The SITA algorithm for the HFA perimeter ${ }^{13}$ and the high-pass resolution perimeter $(\mathrm{HRP})^{14}$ are examples of this attempt. The examination time with both these methods is $4-7 \mathrm{~min}$.

The aim of the present study was to evaluate the influence of VF examinations using modern techniques with short examination times on the IOP.

\section{Materials and methods}

Sixty-one consecutive patients, aged 28-90 years, 40 women and 21 men, were examined in two clinical settings at the St Eriks Eye Hospital, 21 at the Glaucoma service and 40 at a general outpatient clinic. Forty patients were treated for glaucoma and 21 were untreated patients with ocular hypertension or suspected glaucoma.

All subjects underwent a standard procedure with the same order of the examinations; first
Department of Clinical Neuroscience, Section of Ophthalmology and Vision, Karolinska Institutet, Stockholm, Sweden

Correspondence: L Martin, Department of Clinical Neuroscience,

Section of Ophthalmology and Vision,

Karolinska Institutet, St Eriks Eye Hospital, S-112 82 Stockholm, Sweden

Tel: +46867236 68;

Fax: + 4686733330 .

E-mail: lene.martin@ste.ki.se

Received: 19 February 2006 Accepted in revised form: 5 July 2006

Published online: 6 October 2006 
the visual acuity measurement, followed by tonometry, VF examination, the second tonometry, biomicroscopy, and last funduscopy. Applanation tonometry using the Goldmann principle was performed immediately before and immediately after the VF examinations. Four welltrained ophthalmic nurses or technicians performed all examinations. It was always the same nurse/technician who performed the first and the second IOP measurement and the VF examinations in the same patient.

Twenty-one subjects were examined using the HFA and 40 with the HRP. The HFA examination was performed using the SITA Standard or the SITA Fast test strategies, during mesopic adaptation, with an undilated pupil and a correction according to the patient's refraction, age, and examination distance $(0.33 \mathrm{~m})$. The HRP examinations were performed under fotopic adaptation, with an undilated pupil and a correction according to the patient's refraction and examination distance $(0.167 \mathrm{~m})$. All patients wore an addition of $6 \mathrm{D}$ owing to the short examination distance, leading to an examination performed without accommodation. All patients were familiar with the VF examination techniques.

The VF examination times and the IOP readings before and after the VF examinations were recorded.

Statistical analyses were performed using Student's t-test, Fisher's exact test, and Spearman Rank correlation test. A $P$-value of 0.05 was regarded as significant.

\section{Results}

A difference in IOP of more than $2 \mathrm{~mm}$ before and after the VF examination was observed in 14 of the 61 patients $(23 \%)$. The mean, SD, and range are shown in Table 1 . In eight subjects, the IOP increased in one (the other eye unchanged) or both eyes; in 15 subjects, a decrease was found in one (the other eye unchanged) or both eyes. The maximum change in each direction was $4 \mathrm{~mm} \mathrm{Hg}$. The mean differences were not significant. No differences were observed between gender, patient groups, clinical settings, or examiners, and no correlation was found

Table 1 IOP before and after VF examinations

\begin{tabular}{lrrlrrc}
\hline & $\begin{array}{c}\text { IOP1 } \\
\text { RE }\end{array}$ & $\begin{array}{c}\text { IOP2 } \\
\text { RE }\end{array}$ & $\begin{array}{c}\text { Diff } \\
\text { RE }\end{array}$ & $\begin{array}{r}\text { IOP1 } \\
\text { LE }\end{array}$ & $\begin{array}{r}\text { IOP2 } \\
\text { LE }\end{array}$ & $\begin{array}{c}\text { Diff } \\
\text { LE }\end{array}$ \\
\hline Mean & 16.15 & 15.85 & 0.3 & 16.53 & 16.05 & 0.63 \\
SD & 3.36 & 3.93 & 1.66 & 4.73 & 4.41 & 1.83 \\
Range & $10-26$ & $9-27$ & $-4-4$ & $10-29$ & $10-27$ & $-4-4$ \\
\hline
\end{tabular}

IOP1, IOP immediately before VF examination; IOP2, IOP immediately after VF examination; RE, right eye; LE, left eye; Diff, difference between IOP1 and IOP2.
Table 2 Visual field examination time ( $\mathrm{min}$ )

\begin{tabular}{lcccc}
\hline & HFA RE & HFA LE & HRP RE & HRP LE \\
\hline Mean & 3.75 & 3.72 & 5.5 & 5.77 \\
SD & 1.01 & 0.99 & 1.06 & 0.73 \\
Range & $2.49-6.36$ & $2.49-6.35$ & $1.58-7.16$ & $2.26-7$ \\
\hline
\end{tabular}

HRP, high-pass resolution perimetry; HFA, Humphrey visual field analyser; $R E$, right eye; LE, left eye.

between age and IOP change. All eight subjects with increasing IOP after VF examinations were examined using the HRP technique $(P=0.04)$.

The examination time for the HFA was statistically shorter $(P<0.0001)$ than for the HRP, see Table 2.

\section{Discussion}

The present study did not show any significant difference in IOP readings before and after VF examination in the examined group. No differences were seen between patients with manifest glaucoma and patients with ocular hypertension or suspected glaucoma, between older and younger, between genders, examiners, or between the two clinical settings.

In clinical settings and in ophthalmic training courses, the question often arises about the most appropriate time to measure the IOP before or after the VF examination. The reason for measuring the IOP before the VF is that all examinations but the VF examination often are performed in the same room, whereas the VF examination takes place in another room at the clinic. Thus, it is more convenient to measure the IOP, together with performing visual acuity measurement, slit-lamp examinations, etc before the VF examination. This is presumably the most common procedure in Sweden (L Martin, unpublished data). However, after tonometry, some patients experience slightly blurred vision, which might influence the VF result. Therefore, many clinics prefer to measure IOP after the VF examination.

Recupero $e t a l^{12}$ studied IOP before and after VF examinations in 13 normal subjects and 49 glaucoma patients. They found an IOP increase of more than $2 \mathrm{~mm}$ $\mathrm{Hg}$ in $45 \%$ of the glaucoma patients, with a mean increase of $5.5 \mathrm{~mm} \mathrm{Hg}$ (range in the total group -6-11 mm $\mathrm{Hg}$ ). These results clearly differ from the observations in the present study, where the mean difference was 0.3 and $0.65 \mathrm{~mm} \mathrm{Hg}$ for the right and left eye, respectively, and the largest difference in any direction was $4 \mathrm{~mm} \mathrm{Hg}$. However, in the study by Recupero, the VF examinations took 7-18 min, whereas in the current study only two examinations slightly exceeded $7 \mathrm{~min}$. The difference in examination time may be the reason for the divergent results. Relaxed accommodation has been proposed as a possible mechanism for IOP increase after VF 
examinations ${ }^{12,15,16}$ as well as psychic stress, ${ }^{17}$ among other factors. ${ }^{10}$ In the current study, all patients that showed an, albeit small, IOP increase after the VF were examined using the HRP technique. This examination is performed with totally relaxed accommodation, with the addition of $+6 \mathrm{D}$ to the patient's distance correction, in order to fully compensate for the short viewing distance $(0.167 \mathrm{~m})$. In the HFA, the patients use age-related correction in addition to their own distance refraction for near vision, which leaves some room for active accommodation that might influence the IOP. Regarding psychic stress, studies have reported patient preference for HRP compared to other methods ${ }^{14,18}$ and the patients in the study were familiar with the used techniques, which makes psychic stress an unlikely explanation for the IOP increase from HRP. The variation in IOP found in the current study was also very small and well within the previously described normal variability of $2-3 \mathrm{~mm} \mathrm{Hg}$ between examinations. ${ }^{10,11}$

The findings in the current study indicate that IOP measurement can be performed after the VF examination and clinically relevant IOP values obtained, provided that VF techniques with short examination time are used.

\section{References}

1 Leske MC, Heijl A, Hussein M, Bengtsson B, Hyman L, Komaroff E, Early Manifest Glaucoma Trial Group. Factors for glaucoma progression and the effect of treatment: the early manifest glaucoma trial. Arch Ophthalmol 2003; 121(1): 48-56.

2 Aggarwala KR. On the short-term variability of measurements of intra-ocular pressure. Optom Vis Sci 1995; 72(10): 753-755.

3 Brandt JD, Beiser JA, Kass MA, Gordon MO. Central corneal thickness in the Ocular Hypertension Treatment Study (OHTS). Ophthalmology 2001; 108(10): 1779-1788.

4 Feltgen N, Leifert D, Funk J. Correlation between central corneal thickness, applanation tonometry, and direct intracameral IOP readings. Br J Ophthalmol 2001; 85(1): 85-87.
5 Lleo A, Marcos A, Calatayud M, Alonso L, Rahhal SM, Sanchis-Gimeno JA. The relationship between central corneal thickness and Goldmann applanation tonometry. Clin Exp Optom 2003; 86(2): 104-108.

6 Rota-Bartelink AM, Pitt A, Story I. Influence of diurnal variation on the intra-ocular pressure measurement of treated primary open-angle glaucoma during office hours. J Glaucoma 1996; 5(6): 410-415.

7 Brucculeri M, Hammel T, Harris A, Malinovsky V, Martin B. Regulation of intra-ocular pressure after water drinking. J Glaucoma 1999; 8(2): 111-116.

8 Jamal KN, Gurses-Ozden R, Liebmann JM, Ritch R. Attempted eyelid closure affects intra-ocular pressure measurement in open-angle glaucoma patients. Am J Ophthalmol 2002; 134(2): 186-189.

9 Teng C, Gurses-Ozden R, Liebmann JM, Tello C, Ritch R. Effect of a tight necktie on intra-ocular pressure. $\mathrm{Br} J$ Ophthalmol 2003; 87(8): 946-948.

10 Whitacre MM, Stein R. Sources of error with use of Goldmann-type tonometers. Surv Ophthalmol 1993; 38(1): 1-30.

11 Sudesh S, Moseley MJ, Thompson JR. Accuracy of Goldmann tonometry in clinical practice. Acta Ophthalmol (Copenhagen) 1993; 71(2): 185-188.

12 Recupero SM, Contestabile MT, Taverniti L, Villani GM, Recupero V. Open-angle glaucoma: variations in the intra-ocular pressure after visual field examination. J Glaucoma 2003; 12(2): 114-118.

13 Bengtsson B, Heijl A. Normal intersubject threshold variability and normal limits of the SITA SWAP and full threshold SWAP perimetric programs. Invest Ophthalmol Vis Sci 2003; 44(11): 5029-5034.

14 Frisén L. High-pass resolution perimetry. A clinical review. Doc Ophthalmol 1993; 83(1): 1-25.

15 Armaly MF, Rubin ML. Ackommodation and applanation tonometry. Arch Ophthalmol 1961; 65: 604-614.

16 Patsea LE, Amariotakis A, Katsourakis S, Roungas K, Skouriotis S, Vourexaki M et al. IOP increase after visual field examination. 3rd International Glaucoma Symposium: 22-25 March, 2001; Praque. Czech Republic.

17 Brody S, Erb C, Veit R, Rau H. Intra-ocular pressure changes: the influence of psychological stress and the Valsalva maneuver. Biol Psychol 1999; 51(1): 43-57.

18 Lindblom B, Hoyt WF. High-pass resolution perimetry in neuro-ophthalmology. Clinical impressions. Ophthalmology 1992; 99(5): 700-705. 